to replace the existing (overwhelmingly foreign) workforce, and receive a sudden onslaught of newly minted Saudi human resource. In such a situation, academia has been able to absorb substantial numbers of citizens, mainly into administrative positions, but also as part-time lecturers, lab technicians, research assistants, and other support functions.

As an ongoing phenomenon, Saudization within universities is bound to evolve. The Kingdom continues to devote substantial resources toward the development of a world-class higher education system. However, labor market pressures to urgently localize the workforce must be handled thoughtfully. The ministry of education should formulate its own recommendations for Saudization. One could be a more gradual Saudization of administrative positions in higher education, and, accompanying this, thorough training and exposure to international norms of teaching and research for Saudi administrative staff. More locally suited quality assurance mechanisms for faculty members and senior staff with regard to teaching, research, and service-the three essential aspects of the academic experience-should be introduced. Finally, academic preparation at all levels-from college preparatory years to university curricula themselves - must be made more rigorous. This is essential in order for Saudi universities to be able to do their job well: that of educating the country's young citizens to a relevant and employable standard.

\section{Luxembourg's Expanding Higher Education System: Responding to Global Norms}

\section{Gangolf Braband and justin J. W. Powell}

Gangolf Braband is research fellow at the University of Luxembourg. E-mail: gangolf.braband@uni.lu. Justin J.W. Powell is professor at the University of Luxembourg. E-mail: justin.powell@uni.lu.

$\mathrm{T}$ The worldwide expansion of higher education bypassed Luxembourg for some time. In the absence of a national research university, the Grand Duchy lacked capacity for teaching and research. This seemed increasingly anomalous given the rise of the "knowledge economy," especially because Luxembourg, with a population of 543,000, unlike many other small states, is unusually international, ethnically diverse, and prosperous. Luxembourgers seeking to complete a university degree traditionally did so abroad.
Initially, this was not perceived as a disadvantage, but was seen as beneficial in forming a distinguished national elite with European networks. Few incentives existed to expand domestic higher education.

The situation shifted toward the end of the I990s, due to the ongoing expansion of higher education internationally, and Europeanization processes like the Bologna Process and the European Commission's Lisbon Strategy. Indeed, Luxembourg's minister in charge of higher education signed the Bologna declaration in I999-years prior to the founding of the University of Luxembourg (UL), the first and only state-funded national university.

\section{Establishing the First National University in LUXEMBOURG}

Early attempts to establish a university in Luxembourg in the Igth and 2oth centuries failed, thereby initiating the study-abroad tradition, with a practice characterized by an initial period of study of two years in Luxembourg prior to going abroad, and close connections between students abroad and political and societal elites at home, creating a well-defined and closed circle of leaders. Given this environment, the drive for change had to come from the outside. The first research framework program of the European Union (1984) provided such an impulse, but ultimately its effects on higher education were limited. Further international developments triggered only incremental changes. No public pressure counteracted this lack of political willingness to innovate: Higher education was simply not a public issue.

The internationalization of higher education, in the meantime, gained more weight and influenced the country's further development. A few powerful political actors in the responsible ministry instrumentalized the tools provided by the Bologna Process and by the Lisbon Strategy (here especially the demand for increasing investments into research and innovation), to counteract the prevailing opposition and raise awareness. The idea was to create a stronger institutional basis for publically funded research, by establishing a university focusing on graduate degree programs in selected fields aligned to national needs. While keeping the study abroad tradition alive, such a university would expand higher education opportunities, simultaneously contributing to the diversification of the country's economic basis and bolstering Luxembourg's "knowledge economy."

Ultimately, the aim of founding a university was successful, yet in a rather controversial manner, through a top-down process par excellence, characterized by a lack of transparency and few attempts to engage the wider society. The outcome of this approach was not as initially anticipated. Existing postsecondary education institutions were 
incorporated, expanding the university's teaching dimension with a range of bachelor's and vocational programs. The turnaround was nevertheless remarkable: Within a few years, a national research-oriented university went from being a non-topic to a legal reality.

\section{An (INTER) National Research University}

Somewhat paradoxically, at the same time that European borders are becoming more porous and spatial mobility everywhere is supported and glorified, Luxembourg has invested considerable capital and strategic planning in (finally) establishing its national university. It aims to compete globally by concentrating its intellectual and financial resources, and by building on the country's strengths and priorities. It may have taken a leap of faith to establish the university in 2003 , but the state-led by a few dedicated actors-took the step to fund this ambitious experiment in scientific capacity-building. In so doing, it also provided a stay-at-home alternative for Luxembourg's youth. UL was founded against considerable resistance, both pecuniary and ideological, due to the long-standing custom of educating elites abroad to establish cosmopolitan networks. But rising international competition and supranational coordination have increased pressure on Luxembourg to grow its higher education system and thus foster scientific innovation. UL provides a means to diversify the economy beyond steelmaking or banking, and to integrate citizens from diverse cultural backgrounds into a polity dominated by local elites. Oriented toward the Grand Duchy's unique context-small size, but simultaneously flourishing center of European governance and international business-UL was founded upon the principles of internationality, multilingualism, and interdisciplinarity.

With courses of study taught in English, German, and French, UL enjoys a rising reputation, as it provides a gauge of the impact of global norms generally, and the principles codified in the Bologna Process specifically. UL exemplifies the most recent institutionalization phase of the European university. Due to its recent establishment, UL has straightforwardly assumed European standards-and with more than half of its 6,287 students (2014-2015) coming from abroad, UL is extraordinarily diverse. Regardless of nationality, each student pays a tuition of just $€ 200$ per semester. Thus, state investment in higher education ensures broad access, attracting students from everywhere. In a hyperdiverse society marked by extraordinary migration flows and mobility, internationalization has been key to the establishment and expansion of the university. To develop an institution based on local strengths, regional needs, and global trends, UL aims to achieve excellence by recruiting top faculty members worldwide, and by identifying in advance research areas that reflect Luxembourg's economic and geographic contexts. Focusing on key priorities and excelling in international collaborations, the chosen strategy has shown positive results, with UL now ranked I93th worldwide (Times Higher Educations World University Rankings 2015-2016).

\section{Future Challenges}

Higher education in Luxembourg has fundamentally changed. Before the founding of the university, issues of higher education were of limited relevance to societal and political discussions. And herein lays a challenge. An institution that was initially disputed, coming to life only through the considerable engagement of a few key actors rather than relying on bottom-up societal processes, needs such support to advance beyond simply meeting national economic needs or being fully legitimated politically. UL requires support to attain greater institutional autonomy, moving beyond the stage of being a political instrument to that of an organization governed by academic principles. UL has managed to rapidly establish a remarkable international reputation and to further advance Luxembourg's internationalization. Yet, this success poses a challenge, as the diversity of its members and the accommodation of different higher education cultures-in the absence of a preexisting national consensus-affect the university's internal organization and its governance.

However small, no country wishing to become a "knowledge society" can do so without an (inter)national research university. As many larger countries in Europe struggle to maintain their state-funded universities in the Bologna era, Luxembourg has grasped a window of opportunity. The university's extremely high degree of internationalization provides thereby contemporary strength, but this does not in itself facilitate the organization's greater societal and cultural integration within Luxembourg. Without placing the university more solidly in the country's politics, culture, and identity, while enhancing its organizational autonomy, it remains a project vulnerable to the vagaries of policymakers. 